\title{
Contribution of Imaging Techniques in the Management of Cutaneous Pathology
}

\author{
IOANA ALINA GRAJDEANU ${ }^{1}$, LAURA STATESCU ${ }^{1,2}$, DAN VATA ${ }^{1,2 *}$, CRISTINA GRIGORESCU ${ }^{3}$, IOANA ADRIANA POPESCU ${ }^{1,2 *}$, \\ ELENA PORUMB ANDRESE ${ }^{1,2}$, TATIANA TARANU ${ }^{4,5}$, ALEXANDRU PATRASCU ${ }^{6}$, LAURA SO LOVASTRU GHEUCA ${ }^{1,2}$ \\ ${ }^{1}$ Grigore T. Popa University of Medicine and Pharmacy, Faculty of Medicine, Dermatology Department, 16 Universitatii Str., \\ 700115, Iasi, Romania \\ 2Dermatology Clinic, St. Spiridon County Emergency Clinical Hospital, 1 Independentei Sq., 700111, lasi, Romania \\ ${ }^{3}$ Grigore T. Popa University of Medicine and Pharmacy, Faculty of Medicine, Thoracic Surgery Department, 16 Universitatii Str., \\ 700115, lasi, Romania \\ ${ }^{4}$ Grigore T. Popa University of Medicine and Pharmacy, Faculty of Dental Medicine, Dermatology Department, 16 Universitatii \\ Str., 700115, lasi, Romania \\ ${ }^{5}$ Dermatology Clinic, CF lasi Hospital,1 Garabeti Braileanu, 700506, Iasi, Romania \\ ${ }^{6}$ Grigore T. Popa University of Medicine and Pharmacy, Faculty of Medicine, Orthopaedic Department, 16 Universitatii Str., \\ 700115, lasi, Romania
}

\begin{abstract}
The management of skin pathology of tumors and inflammatory disorders is difficult due to the existence of constantly changing diagnostic and treatment algorithms. The incidence of cutaneous melanoma and other melanocytic or non-melanoma tumors is currently increasing. Melanoma is difficult to treat in advanced stages due to its aggressiveness, and early diagnosis is required to improve the prognosis of these patients. Imaging techniques, such as classical and digital dermatoscopy can provide information on structure, vascular pattern, prognostic factors and detailed morphological analysis that can lead to improved individual management. This article presents a retrospective study that aims to analyze the contribution of imaging techniques to clinical and histological data.
\end{abstract}

Keywords: skin tumors, dermatoscopy, melanoma, melanocytic nevi

The management of tumor and inflammatory skin pathology falls within the area of interest in current scientific and applied scientific research due to the increased frequency of these diseases and the existence of constantly changing diagnostic and treatment algorithms is requiring standardization. The incidence of skin tumors is steadily rising, with more than one patient diagnosed with other cancers in the last three decades [1]. In recent years, malignant melanoma and non-melanoma skin neoplasms have become an increasingly common form of cancer [2]. Melanoma accounts for less than $1 \%$ of the percentage of cutaneous tumors but accounts for the highest mortality rate, and therefore screening methods and diagnosis with high sensitivity and specificity are required to reduce mortality. Although the clear method of diagnosing tumor lesions is histopathological examination, non-invasive methods, such as digital dermatoscopyalong with high frequency ultrasound, offer the possibility of increasing reliability of diagnosis correctness, establishing prognostic factors and therapeutic management with the possibility of avoiding invasive maneuvers [3-5]. Having been considered stethoscope of the dermatologist, dermatoscopy is used primarily to assess benign tumor lesions (melanocytic nevi, lentigo, seborrheic keratoses, dermatofibromas) and detect skin malignant lesions such as malignant melanoma, basal cell carcinomas or squamous cell carcinomas.

This article presents a retrospective study that aims to evaluate whether imaging investigations provide additional information that helps to increase diagnostic accuracyand the possibility of individualizing the treatment of skin lesions of the tumor type.

\section{Experimental part}

Materials and methods

The retrospective observational study was conducted after obtaining approval from the Institutional Ethics Commission. Patients between 18 to 75 years old with high-risk, intermediate or non-malignant pigmentary and nonpigmentarytumoral lesions were admitted at the St. Spiridon Hospital Dermatology Clinic and the offices in which doctors were working between 2015 and 2017.

Excluded from the study were patients presenting neuropsychiatric pathology, deep neoplastic pathology, tumor lesions that had already undergone one or more surgical procedures, such as biopsy or excision, infected or with significant bleeding. A clinically integrative, dermatoscopic, histopathological analysis was performed and these data were introduced into the database and statistically analyzed using the Statistics 7 software.

\section{Results and discussions}

The study included at this stage a total of 38 patients diagnosed with pigmentary or non-pigmentary tumoral lesions. The following diagnostic imaging tests were used:

- Manual dermatoscopy. for the examination of tumor lesions, a non-polarized dermatoscope and / or dermatoscope with polarized light, with or without immersion fluid, were used depending on the type of tumor being analyzed.

- Videodermatoscopy (digital dermatoscopy): A videodermatoscope was used to store images and assisted computer analysis by obtaining a DANAOS score for each tumor lesion.

- The histopathological examination is the gold standard diagnostic method in the evaluation of pigmentary and

\footnotetext{
*email:danvata@yahoo.com; oana.manolache@yahoo.com;
} 
non-pigmentary tumoral lesions, which analyzes in optical microscopy. Immunohistochemistry data are useful in the assessment of various pathologies as well as in cases of skin lesions where classical investigations do not provide conclusive data $[6,7]$.

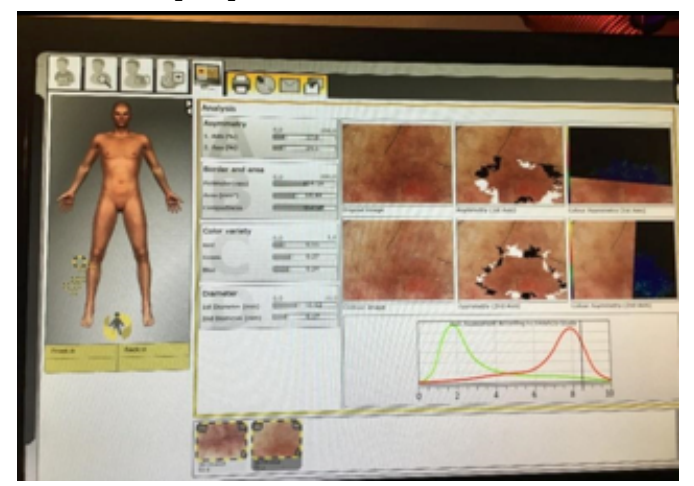

Fig. 1. Videodermatoscopy - example of the analysis of asymetry, margins, dimensions, colors and the appearance of malign risk through the danaos score

The analysis of the data shows that $63.1 \%$ of the registered patients were female and $36.9 \%$ male, with an average age of 41.05 years, ranging from 18 to 70 years. $89.48 \%$ of the patients came from an urban environment, and $34.3 \%$ of the patients said they had used photoprotection products during exposure to the sun. Patients reported a personal history of cardiovascular disease (hypertension, ischemic cardiopathy), vulgar psoriasis, autoimmune thyroiditis and operated breast cancer.

Figure 2 shows that the excised lesions had the following topography: $16 \%$ anterior thorax, $34 \%$ posterior thorax, 26\% head and cervical region, 16\% upper limbs, $8 \%$ lower limbs, with no mucosal involvement.

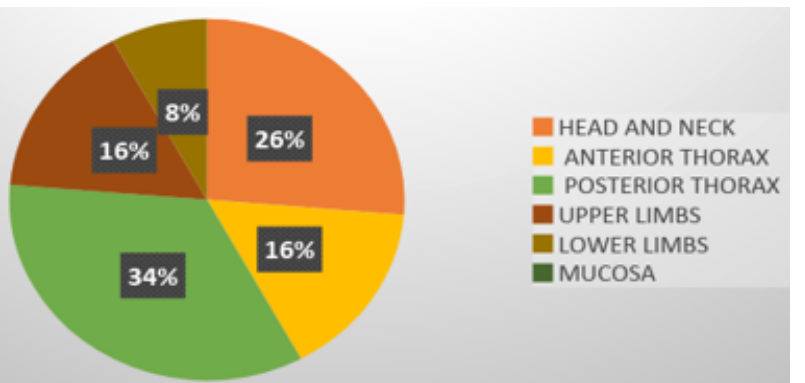

Fig. 2. Topographic distribution of tumoral lesions

Pigmented or non-pigmented malignant tumors, suspected tumors, as well as benign tumors in which patients have requested excision for repeated trauma or aesthetic reasons, have been excised with surgical safety limits, and the samples were subsequently examined histopathologically using the Hematoxylin Eosin staining. If we consider that the histological examination provides the gold standard diagnosis, then we can compare the degree of correlation between the results of the clinical examination and the dermatoscopic examination with the results of the histological examination. Clinical and histological examinations revealed cases of benign tumors, cases of suspected malignant tumors and cases of malignant tumors, as presented in the table 1 and figure 3.

As can be seen, $10.53 \%$ of cases were diagnosed as suspected malignant by clinical examination and $2.63 \%$ of cases by histological examination, the difference being almost statistically significant at $p<0.10: p=0.05>t=$ 1.389> $p=0.10$. Considering positive cases those cases diagnosed as malignantand those diagnosed as suspected of malignancy, we compared histological diagnosis with clinical and dermatoscopic diagnosis.

Table 1

FREQUENCY OF DIAGNOSTIC CAUSES BY CLINICAL AND HISTOLOGICAL EXAMINATION

\begin{tabular}{|c|c|c|c|c|c|c|c|}
\hline \multirow{3}{*}{ Diagnosis } & \multicolumn{6}{|c|}{ Tumors } & \multirow{3}{*}{ Total } \\
\hline & \multicolumn{2}{|c|}{ Benign } & \multicolumn{2}{|c|}{ Suspected of malignancy } & \multicolumn{2}{|c|}{ Malignant } & \\
\hline & $\mathrm{N}$ & $\%$ & $\mathbf{N}$ & $\%$ & $\mathrm{~N}$ & $\%$ & \\
\hline Clinical & 29 & 76.32 & 4 & 10.53 & 5 & 13.16 & 38 \\
\hline Histological & 31 & 81.58 & 1 & 2.63 & 6 & 15.79 & 38 \\
\hline
\end{tabular}

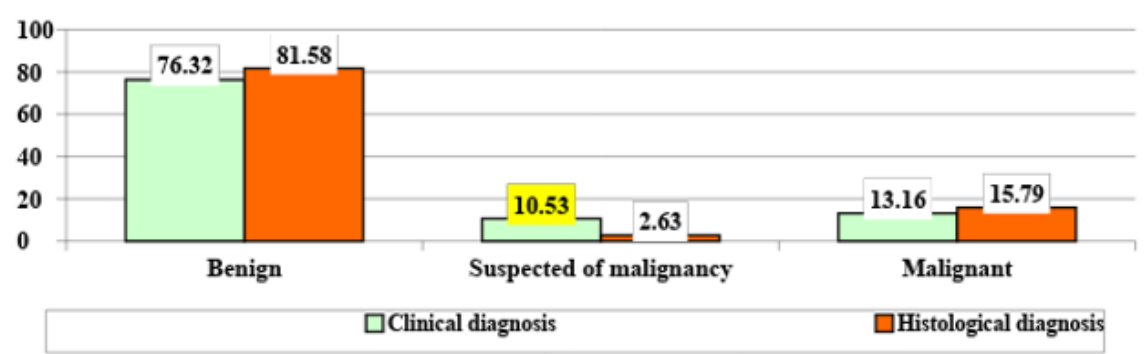

Fig. 3. Differences between frequency of tumors observed by cinical and histological diagnosis

Comparison of clinical and histological diagnosis:

\begin{tabular}{|c|c|c|c|}
\hline \multirow{2}{*}{ Clinical Diagnosis } & \multicolumn{2}{|c|}{ Histologic Diagnosis } & \multirow{2}{*}{ Total } \\
\cline { 2 - 4 } & Positive & Negative & 10 \\
\hline Positive & 8 real positive & 2 false positive & 28 \\
\hline Negative & 0 false negative & 28 real negative & 38 \\
\hline Total & 8 & 30 & \\
\hline
\end{tabular}

Table 2

FREQUENCY OF CAUSES BY CLINICAL AND HISTOLOGICAL DIAGNOSIS 


\begin{tabular}{|l|c|c|}
\hline \multicolumn{1}{|c|}{ Statistic } & Value & $95 \%$ Confidence Interval \\
\hline Sensitivity & $100 \%$ & $63.06 \%$ to $100 \%$ \\
\hline Specificity & $93.33 \%$ & 77.93 to 99.18 \\
\hline Positive Likelihood Ratio & 15.00 & 3.93 to 57.22 \\
\hline Negative Likelihood Ratio & 0 & \\
\hline Prevalence & $21.05 \%$ & $9.55 \%$ to $37.32 \%$ \\
\hline Positive Predictive value & $77.78 \%$ & $47.21 \%$ to $93.20 \%$ \\
\hline Negative Predictive Value & $100 \%$ & \\
\hline Accuracy & $94.74 \%$ & $82.25 \%$ to $99.36 \%$ \\
\hline
\end{tabular}

Table 3

RESULTS OF COMPARISON OF HISTOLOGICAL CLINICAL DIAGNOSIS

Comparison of dermatoscopic diagnosis assessed by malignant, suspected or benign tumor with histologic diagnosis

\begin{tabular}{|c|c|c|c|}
\hline \multirow{2}{*}{ Dermatoscopic } & \multicolumn{2}{|c|}{ Histologic examination } & \multirow{2}{*}{ Total } \\
\cline { 2 - 3 } & Positives & Negatives & \\
\hline Positives & 7 real positives & 2 false positives & 9 \\
\hline Negatives & 1 false negative & 28 real negatives & 29 \\
\hline Total & 8 & 30 & 38 \\
\hline
\end{tabular}

Dermatoscopy is a non-invasive, practical and timesaving method that allows the diagnosis and evaluation of tumor morphological parameters that may or may not be detected in the clinical examination of cutaneous lesions, and studies show that this method improves the accuracy of clinical diagnosis by $20-30 \%$ [8].

In order to establish a dermatoscopic diagnosis, several diagnostic algorithms have been described over time. Most have the primary purpose of differentiating melanocytic lesions from non-melanocytic lesions. Subsequently, melanocytic lesions determine the benign or malignant nature. The ABCDE rule is one of the most common methods used in the clinical evaluation of pigment injuries. In this semiquantitative model, each of the four criteria is assigned a score, based on a calculation formula, the total dermatoscopic score (SDT) is determined. Other algorithms can be used such as:

a. The 7 improved criteria consisting of: atypical network, atypical vessels, white-blue veil (all valued at 2 points), regression structures, irregular dots / globules, irregular blotches - the presence of a single criterion is sufficient to perform a biopsy; and the presence of more than 2 points is equivalent to melanoma.
Table 4

FREQUENCY OF CASES BY DERMATOSCOPIC DIAGNOSIS APPEARED THROUGH PRESENT / ABSENT MALIGNANT RISK AND HISTOLOGY

b. Pattern analysis - descriptive method.

c. The two-step algorithm: determining whether or not the tumor is melanocytic, and in the second stage establishing the type of tumor (nevus or melanoma).

$d$. The Menzies method consists of the presence of negative characteristics (symmetric pattern, the presence of a single color) and positive features of melanoma - in which the diagnosis of melanoma consists in the absence of negative characteristics and the presence of at least one positive characteristic.

Digital dermatoscopy is a modern method of diagnosis and assessment of skin tumors, especially pigmentary lesions, using video digital imaging, a powerful tool with the ability to memorize, analyze images and compare them over a period of time to track the evolution of cutaneous lesions. The images obtained from the videodermatoscopic examination can be analyzed by the clinician and can also be evaluated by assisted computer analysis system by calculating the DANAOS score based on the Artificial Intelligence principle. Digital dermatoscopy may allow early detection of malignant tumor lesions, the DANAOS score obtained from dermatoscopic analysis of tumors may range from 0 to 10, with values less than 4.75 being attributed to benign lesions, values greater than 5.45 for

\begin{tabular}{|l|c|c|}
\hline \multicolumn{1}{|c|}{ Statistic } & Value & 95\% Confidence Interval \\
\hline Sensitivity & $87.5 \%$ & $47.35 \%$ to $99.68 \%$ \\
\hline Specificity & $93.33 \%$ & 77.93 to 99.18 \\
\hline Positive Likelihood Ratio & 13.13 & 3.35 to 51.36 \\
\hline Negative Likelihood Ratio & 0.13 & 0.02 to 0.84 \\
\hline Prevalence & $21.05 \%$ & $9.55 \%$ to $37.32 \%$ \\
\hline Positive Predictive value & $80 \%$ & $51.18 \%$ to $93.85 \%$ \\
\hline Negative Predictive Value & $96.55 \%$ & $81.70 \%$ to $99.43 \%$ \\
\hline Accuracy & $92.11 \%$ & $78.62 \%$ to $98.34 \%$ \\
\hline
\end{tabular}

Table 5

RESULTS OF THE COMPARISON BETWEEN DERMATOSCOPIC DIAGNOSTIC APPRECIABLE BY MALIGNANT RISK / SUSPECTED LESION 


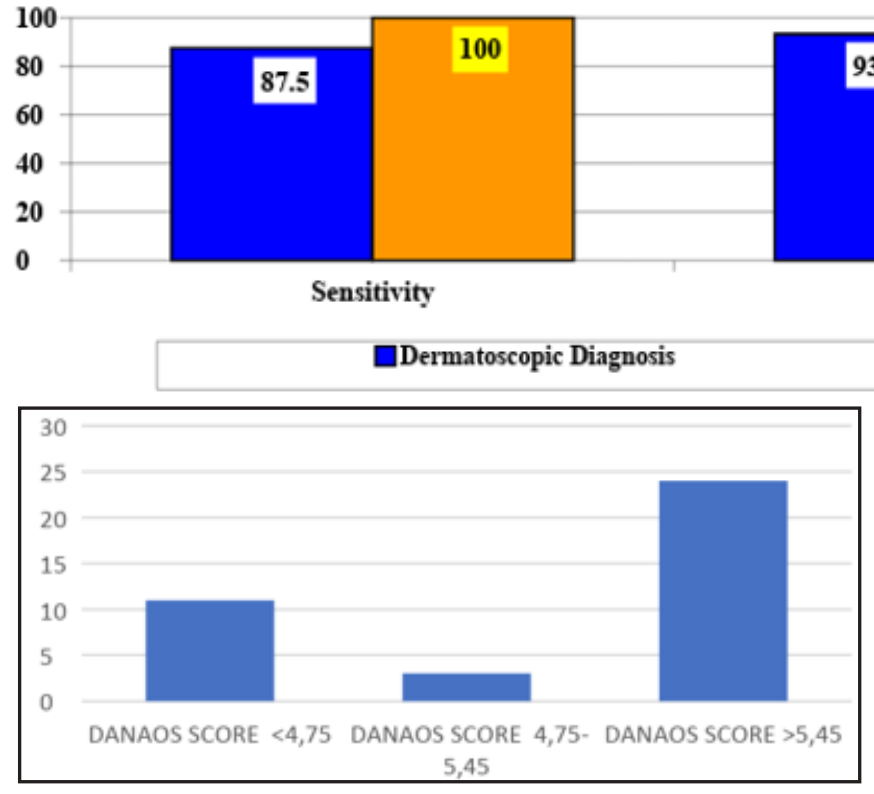

Fig. 5. Tumor repartition by danaos videodermatoscopic score
Fig. 4. Differences between the sensitivity and specificity of histological diagnosis and the determination of dermatoscopic malignancy risk / suspected lesions

Specificity

$\square$ Histological Diagnosis

The prognosis score of the DANAOS score was correlated with the low malignant dermatoscopic score with values lower than 4.75 in $28.94 \%$ of cases, values between 4.75 and 5.45 in $7.89 \%$ of cases and an increased risk of malignancy was attributed with values greater than 5.45 in $63.17 \%$ of cases.

The most common type of tumor analyzed was the compound melanocytic nevus (26.32\%). The comparison of the frequency of the types of tumors diagnosed clinically and histopathologically revealed as shown in table 6 the following differences:

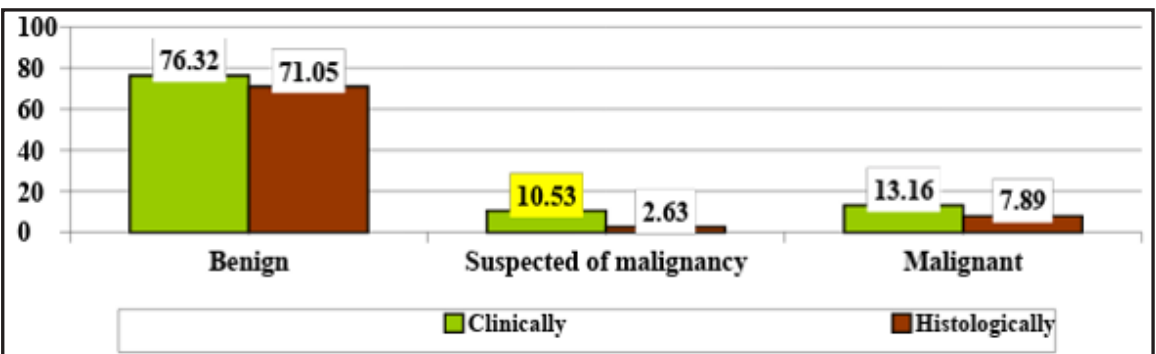

Fig. 6. Frequency of causes by type clinical and histological diagnosis tumors dysplastic and especially those above 7.5 in malignancies [9].

The sensitivity of the digital dermatoscopy analysis was reported to be between $80 \%$ and $100 \%$ [10] and the specificity between 46 and $98 \%$ [11]. Similarly, in our study the sensitivity of the dermatoscopic diagnosis to the assessment of tumor malignancy / suspected tumor risk was $87.5 \%, t=2.248>p=0.01$ and the specificity was recorded as $93.33 \%$ (fig. 4).

Also, computer-assisted digital evaluation of skin tumor lesions provides the possibility of follow-up, particularly in patients with multiple atypical nevi [12], the dermatologist having the ability to compare the parameters of tumor lesions (maximum diameters, surface, asymmetry, margins, variety of color) at predetermined time intervals, as well as to analyze these lesions with the DANAOS score (dynamic values), which allows the possibility of establishing prognostic factors and the therapeutic plan (fig. 5)

\section{Table 6}

DIFFERENCES BETWEEN CLINICAL AND HISTOLOGICAL DIAGNOSIS WITH REGARD TO THE TUMOR TYPE

\begin{tabular}{|c|c|c|c|c|c|}
\hline \multirow{3}{*}{ Tumor type } & \multicolumn{5}{|r|}{ Diagnosis } \\
\hline & \multicolumn{2}{|c|}{ Clinical } & \multicolumn{3}{|r|}{ Histological } \\
\hline & $\mathbf{N}$ & $\%$ & $\mathrm{~N}$ & $\%$ & Differently diagnosed cases \\
\hline Compound melanocytic nevi & 10 & 26,32 & $\begin{array}{l}1 \\
0\end{array}$ & 26,32 & \\
\hline Seborrheic verruca & 6 & 15,79 & 4 & 10,53 & 2: dermal nevi \\
\hline Hemangioma & 2 & 5,26 & 2 & 5,26 & \\
\hline Junctional melanocytic nevi & 2 & 5,26 & 2 & 5,26 & \\
\hline Dermal nevi & 3 & 7,89 & 3 & 7,89 & \\
\hline Verruca vulgaris & 1 & 2,63 & 1 & 2,63 & \\
\hline Dermatofibroma & 1 & 2,63 & 1 & 2,63 & \\
\hline Blue Neví & 3 & 7,89 & 3 & 7,89 & \\
\hline Papilloma & 1 & 2,63 & 1 & 2,63 & \\
\hline Dysplastic melanocytic nevi & 4 & 10,53 & 1 & 2,63 & 2: nodular basal cell carcinoma; 1 : blue nevus \\
\hline Squamous cell carcinoma in situ & 1 & 2,63 & 1 & 2,63 & \\
\hline Nodular basal cell carcinoma & 3 & 7,89 & 1 & 2,63 & 1: dermal nevus; 1 : malignant melanoma \\
\hline Malignant melanoma & 1 & 2,63 & 1 & 2,63 & \\
\hline
\end{tabular}
histopathologically there were 2 cases with non dermal nevi;

- from 4 clinically diagnosed cases with dysplastic melanocytic nevi, histopathologically 2 cases with nodular basal cell carcinoma and 1 case with blue nevi were diagnosed, the difference being significant at $p<0.10 ; p=$ $0.05>t=1.389>p=0.10$

- from 3 clinically diagnosed cases with nodular basal cell carcinoma, histologically one case was diagnosed with non-dermal and 1 case with malignant melanoma.

Differences have not been statistically significant.

Clinically, $5.27 \%$ of cases with benign tumors $(76.32 \%$ compared to $71.05 \%$ histologically diagnosed) were diagnosed with $7.9 \%$ more cases of suspected malignant tumors ( $10.53 \%$ vs. 2 . $63 \%$ histologically diagnosed, the 
difference being almost statistically significant $p=0.05>$ $t=1.389>p=0.10)$ and $5.27 \%$ more cases with malignant tumors (13.16\% histologically diagnosed) (fig. 6).

The limits of this analysis may be given by the reduced number of patients, and data on the study of the effects of dermatoscopy on the current practice of the dermatologist are limited, requiring further research and prospective or retrospective studies in a larger number of patients.

Clarification:

The confidence intervals for sensitivity, specificity and accuracy are exact Clopper-Pearson confidence intervals.

The confidence intervals for Likelihood Ratios are calculated using the Log method.

NOTE

If the prevalence of the disease is known, then the positive and negative predictive value can be calculated using a formula based on Bayes' theorem:

$$
\begin{aligned}
& P P V=\frac{\text { sensitivity } \times \text { prevalence }}{\text { sensitivity } \times \text { prevalence }+(1-\text { specificity }) \times(1-\text { prevalence })} \\
& \text { And respectively: }
\end{aligned}
$$

$$
N P V=\frac{\text { specificity } \times(1-\text { prevalence })}{(1-\text { sensitivity }) \times \text { prevalence }+ \text { specificity } \times(1-\text { prevalence })}
$$

\section{Conclusions}

Taking into account the results obtained in the study, it is observed that the specificity of the dermatoscopic examination with the assessment of the malignant or suspected risk of tumor lesions is comparable to that of the clinical examination with the naked eye. It is also dependent on the examiner and needs a dermatoscopic analysis training to increase sensitivity and diagnostic specificity. It is also noted that videodermatoscopic evaluation with lesion analysis and DANAOS score calculation can not replace clinical examination, but in the case of atypical tumor lesions, this method can give the dermatologist a quick second expert opinion as literature data $[13,14]$. Melanoma can be clinically and sometimes even dermatoscopically not differentiated from benign lesions, representing a challenge for the dermatologist in the formulation of the diagnosis until the histopathological confirmation.

\section{References}

1. STERN RS. Prevalence of a history of skin cancer in 2007: results of an incidence-based model. Arch Dermatol 2010; 146(3):279-282.

2. GHEUCA SOLOVASTRU L, VÂÃ D, STINNCANU A, CIUBARA AM, ANDRESE E. The pshychosocial impact on patients with skin neoplasia.Bulletin of Integrative Pshychiatry2013; 3(58): 33-38.

3. SCHMIDT-WENDTNER MH, Br J Dermatol Dill-Muller D. Ultrasound technology in dermatology. SeminCutanMedSurg 2008; 27: 44-51.

4. GUITERA P, LI LX, CROTTY K ET AL. Melanoma histological Breslow thickness predicted by 75-MHz ultrasonography. $\mathrm{Br}$ J Dermatol 2008; 159:364-369.

5. CRISAN, D., BADEA, A.F., CRISAN, M., RASTIAN I., SOLOVASTRU GHEUCÃ, L., Integrative analysis of cutaneous skin tumours using ultrasonographic criteria. Preliminary results. Med Ultrason 2014;16(4):285-290.

6. SALAHORU, P., GHICIUC, C.M., GRIGORESCU. C., HINGANU, M.V., LUPUSORU, C.E., Use of immunochemistry to establish etiology in the case of primary spontaneous pneumothorax patients. Rev. Chim. (Bucharest), 69, no. 7, 2018, p. 2251-2253.

7. GRIGORESCU, C., GAVRIL, L.C., GAVRIL, L., LINGULEAC, T., CIUNTU, B.M., PATRASCU, A., SALAHORU, P., Anti-receptor Concentration And Over The Clinical Manifestations On Myasthenia Gravis Patients. Rev .Chim (Bucharest), 69, no. 9, 2018, p. 2591-2593.

8. MASOOMEH B, HAIEDEH G, PARISA M, ARASH T., ZAHRA S, MASOOD A.Computer-aided dermoscopy for diagnosis of melanoma. BMC Dermatol 2005; 5:8.

9.SERRAOV, BAPTISTA J, PARIS F, FERREIRA A. Digital dermoscopy. Review of 652 lesions analysed by the DANAOS system. Skin Cancer 2006; 21(4):185-198.

10. ERCAL F, CHAWLA A, STOECKER WV, LEE HC, MOSS RH. Neural network diagnosis of malignant melanoma from color images. IEEE Trans Biomed Eng1994; 41(9):837-45.

11. FARINA B, BARTOLI C, BONO A, COLOMBO A, LUALDI M, TRAGNI $G$, MARCHESINI R. Multispectral imaging approach in the diagnosis of cutaneous melanoma: potentiality and limits. Phys Med Biol 2000; 45(5):1243-54.

12. GREEN A, MARTIN N, PFITZNER J ET AL. Computer image analysis of melanoma in the diagnosis of melanoma. J Am AcadDermatol1994; 31: 958-64.

13. SCHWARZER G, VACH W, SCHUHMACHER M. On the misuses of artificial neural networks for prognostic and diagnostic classification in oncology. Stat Med 2000; 19: 541-61.

14. LISBOA PJ. A review of evidence of health benefit from artificial neural networks in medical intervention.Neural Netw. 2002;15(1):1139.

Manuscris received: 6.08 .2018 